\title{
Social Support for Water Quality: The Influence of Values and Symbolic Racism
}

\author{
Thomas Dietz' \\ Department of Sociology and Environmental Science and Policy \\ Program, Michigan State University, East Lansing, MI, United States \\ Ran Duan \\ Department of Journalism and Environmental Science and Policy \\ Program, Michigan State University, East Lansing, MI, United States \\ Jakob Nalley \\ Department of Integrated Biology and Environmental Science and \\ Policy Program, Michigan State University, East Lansing, MI, United States \\ Anthony Van Witsen \\ Department of Journalism and Environmental Science and Policy \\ Program, Michigan State University, East Lansing, MI, United States
}

\section{Abstract}

Many communities, especially minority communities, have to deal with contaminated water supplies. Remediating such risks is usually expensive, so requires action from state and/or federal governments. In turn, this requires political support for provision of a collective good, an altruistic action. We use data from a Mechanical Turk convenience sample to examine the influence of values and beliefs on donations to remediate water quality, using actual donations to an environmental group as our dependent variable. We find that views about minorities are the strongest predictor of donations, with symbolic racism-beliefs that minorities have received advantageous treatment—substantially reducing donations. In addition, altruistic values have an indirect effect of increasing the likelihood of donating while selfinterested values reduce donations. It appears that support for collective action on water quality is closely tied with both altruism and racial views, suggesting links between research on environmental justice and on environmental decision-making.

Keywords: environmental justice, values, water quality

1 Corresponding author: tdietz@msu.edu. 


\section{Introduction}

In 2010, the United Nations General Assembly declared access to clean water a basic human right (United Nations, 2010). This reflects widespread recognition that improved drinking water quality is a major factor in reducing mortality and enhancing human well-being, but that reliable and affordable access to clean water remains a challenge in many places (Logan \& Walker, 2016; Vorosmarty et al., 2015). Providing clean drinking water is a policy goal in most nations. In developed nations, it has come to be taken for granted as a government responsibility, at least since the rise of the modern environmental movement after 1970 (Andrews, 1999).

Yet water quality problems persist in many parts of the world, and even in the most affluent nations, serious local problems with water quality occur. For example, in 2014, a state-appointed manager for the city of Flint, Michigan, overturned the decision of the elected government and switched Flint's water supply from the Detroit water system to the Flint River. This led to a crisis: lead contamination in drinking water and a severe threat to local health (Michigan Legislature Joint Select Committee on the Flint Water Public Health Emergency, 2016; United States [US] Environmental Protection Agency Office of the Inspector General, 2016). By 2015, Michigan State University pediatrician Mona Hanna-Attisha (2018) raised concerns about the elevated blood lead levels she was observing in Flint children (Bouffard, 2016). Researchers under the direction of Marc Edwards of Virginia Polytechnic Institute discovered that at least a quarter of Flint households had lead levels in their water that exceeded the federal standard of 15 parts per billion (ppb), leading Flint Mayor Karen Weaver to declare a state of emergency (City of Flint, 2015). While Flint is the most visible and perhaps the most tragic water contamination incident in recent US history, there have been serious lead contamination problems in the water of Washington, DC, from 2001-2005 and in Jackson, Mississippi, beginning in 2015. A chemical spill in the Elk River in West Virginia left residents of nine counties without safe drinking water for nearly one week in 2014. In 2015, a toxic chemical used in making plastics contaminated the water supply of Hoosick Falls, New York, and North Bennington, Vermont, until early 2016.

As these problems have unfolded, it has become clear that remediating unsafe drinking water is typically beyond the fiscal and technical capabilities of local governments, even though local governments usually manage water supplies. The estimates for remediating the problem in Flint reach as high as $\$ 1.5$ billion to repair and replace the aging water infrastructure, an amount that is about 1.5 times the combined yearly median income for every household in Flint (Livengood, 2016). Since passage of the Safe Drinking Water Act in 1974, the US federal government has spent more than $\$ 18$ billion to fund improvements in municipal water supplies. This figure does not include the regulatory, research, and training actions of the EPA, and state environmental and health agencies (US Environmental Protection 
Agency, 2016). Clearly, providing safe drinking water requires collective action in which citizens outside an area facing water quality problems contribute to solving the problem through political and financial support. This paper investigates the factors that may influence a willingness, or lack of willingness, to support collective action to ensure safe drinking water in US communities.

We begin by describing three complementary theories that may explain variation in support. Our general logic is that because local communities often cannot fund the costs of dealing with serious water quality problems, the provision of clean water should be viewed as a commons, or collective, good, as are many other forms of environmental quality. The theories may help us understand why some people may support the provision of clean water as a collective good and others may not. All theories center on a key theme in the environmental decision-making literature: that support for environmental quality depends to a substantial degree on altruism - the willingness to contribute to the provision of a public good at a level that reaches beyond the personal benefit one receives.

The first theory derives from well-established literature on environmental values that emphasizes comparing the effects of altruism and self-interest as personal priorities in decision-making, while acknowledging that other values may play a role (Dietz, 2015; Dietz et al., 2005; Steg, 2016). The second theory grows from environmental justice literature (Downey, 2015; Holifield et al., 2017; Mascarenhas, 2016). The examples of Flint, Jackson, Washington, DC, and other work suggests that water quality problems tend to occur disproportionately in poor and minority communities (Balazs \& Ray, 2014). This raises the question of how the minority status of these communities will influence public support for solving water quality problems. Thus, we examine the influence views about minorities play in public support for mediation of water quality problems. Substantial literature in political science has examined the influence of views about minorities, often called symbolic racism, in shaping policy support and political attitudes. In a representative sample of US adults, Chanin (2018) has shown that symbolic racism reduces environmental concern and self-reported willingness to take action to protect the environment and Benegal (2018) finds a link between racism and a lack of concern about climate change. We conjecture that symbolic racism may also play a role in support for collective action to protect water. Finally, recent research on social distance has examined how perceived social distance from those experiencing harm may also be a factor in personal risk perceptions, the source of our third theory. The extent to which people view water quality issues as close to them or affecting people close to them may also influence willingness to support broad remediation efforts (So \& Nabi, 2013).

After reviewing these theories, we described how each was operationalized in a Mechanical Turk survey. We used standard measures of values, of the views about minorities considered indicative of symbolic racism and of social distance to 
predict support for water quality protection. Given the nature of our sample, these results are, of course, preliminary. Our conclusion not only explores their tentative implications for theory and policy, it also suggests directions for further research.

\section{Altruistic values, racism, and social distance}

Altruistic values. Efforts to provide safe drinking water in the US involve local, state, and federal agencies. They use political and financial resources from all three levels. While citizens might be motivated to support safe drinking water efforts in their own community primarily out of self-interest, support for action outside one's own water supply probably requires some degree of altruistic values-concern with the well-being of others. In the environmental decision-making literature, concern with the well-being of other humans, often called humanistic altruism, is sometimes distinguished from concern with other species and the environment, often called biospheric altruism (Dietz, 2015; Steg, 2016; Steg \& de Groot, 2012). The survey measured biospheric altruism, humanistic altruism, and three other values often invoked to explain environmental decisions: self-interest, traditionalism, and openness to change. Self-interested values of course can be oppositional to altruism. We also included a recently proposed set of items intended to capture concern and engagement with non-human animals (Dietz et al., 2017). While animal-related values, traditionalism, and openness to change are not implicated in our theoretical argument about support for clean water, these values have sometimes been shown to influence environmental concern and pro-environmental behavior. Thus, they are included to guard against spurious conclusions regarding altruism. However, our key hypothesis regarding values is that respondents with high degrees of humanistic altruism will be more likely to support efforts to provide clean water to all than will those with lower degrees of humanistic altruism.

Symbolic racism. Humanistic altruism is a concern with all other humans. However, it is also plausible that many people feel altruism in a more restricted way, directed only toward people they consider similar to themselves, where similarity might be defined by nation, shared religion, or race and ethnicity (Richerson \& Boyd, 2001; Richerson et al., 2002; Richerson et al., 2016). Many water quality crises in the US occur in minority communities. The substantial literature on environmental justice suggests this is not surprising; environmental risks are disproportionately visited on minorities (Downey, 2015). The fact that many serious water quality problems occur in minority communities may affect willingness to support collective action to remediate such problems.

We explore this argument by examining whether respondents who hold views that have been labeled symbolic racism may be less willing to support collective action because such action mostly favors minority communities. Racism research notes that some forms of racial tolerance have increased in the US. In particular, there has been a decline in "Jim Crow" racism—that is, racism grounded in beliefs about 
biological differences. However, there are still many individuals who believe that minorities receive unfair advantage and that their problems are largely their own fault_ symbolic racism (Chanin, 2018; Henry \& Sears, 2002; Sears \& Henry, 2005). Symbolic racism has been shown to be a consistent negative predictor of public support for many forms of policy and of environmental concern (Berg, 2013; Buckler et al., 2009; Chanin 2018; O'Brien et al., 2013). We hypothesize that it may also predict support for efforts to improve water quality. We use a scale commonly used in political psychology to test this hypothesis (Henry \& Sears, 2002; Sears \& Henry, 2005; Tarman \& Sears, 2005). Some scholars have argued that the scale we use captures overall conservative views as well as symbolic racism per se (Zigerell, 2015). All our analyses using this scale will also control for political ideology.

Social distance. We have argued that people may be reluctant to contribute to a public good such as water quality when they perceive the recipient of the benefit as someone different from them: a member of a different race or ethnicity. However, we can generalize this idea and suggest that the degree of altruism depends on perceived social distance from the problem and from those who might benefit from its resolution. Social distance can have several dimensions, including temporal distance, spatial distance, and social distance per se (Stephan et al., 2011; Trope \& Liberman, 2010). If risks are perceived to occur at a distance, there will be a tendency to discount the severity of the risk (Zwickle $\&$ Wilson, 2013). The evidence for this hypothesis in the existing literature is mixed. Busse and Menzel (2014) found that the pro-environmental behavior intentions were not predicted by perceived socialspatial distance of the environmental problem. In contrast, Hart and Nisbet (2012) found that varying social distance in message framings influenced support for climate mitigation policies, while Pahl and Bauer (2013) found social distance increased pro-environmental behaviors. We hypothesize that perceived social distance from water quality problems will decrease support for collective action to improve water quality. By including standard measures of social distance along with measures of values and symbolic racism, we are responding to a call for analyses that elaborate on how social distance functions to influence pro-environmental behaviors (McDonald et al., 2015).

\section{Conceptual model}

We consider the variables used in our analysis as constituting a path model with several levels of causal proximity to support for water quality protection (Figure 1). To reduce the chances of spurious attribution of effects to values, symbolic racism, and social distance, we included several other variables in the model: perceived quality of the respondents' drinking water, general awareness of other communities with contaminated water supplies, perceived seriousness of the problem, political ideology, and several sociodemographic characteristics of the respondent. While we 
conceptualize the model as a causal path, we emphasize that our cross-sectional data cannot disentangle causal directions. Given this ambiguity, we will examine the net effects with all variables in the model (i.e., the effects of each variable controlling for the influence of all others) and the total effects in a model with only sociodemographic variables (including political ideology) and values (i.e., the effects of values and sociodemographic factors when not controlling for symbolic racism, social distance, perceived water quality, awareness of other communities, and perceived seriousness).

Note that the questions tapping values, symbolic racism, and perceived quality of the respondents' drinking water were asked before presenting the water quality problem scenario. The questions on social distance, seriousness of the problem, and sociodemographic variables were asked after the scenario was presented.

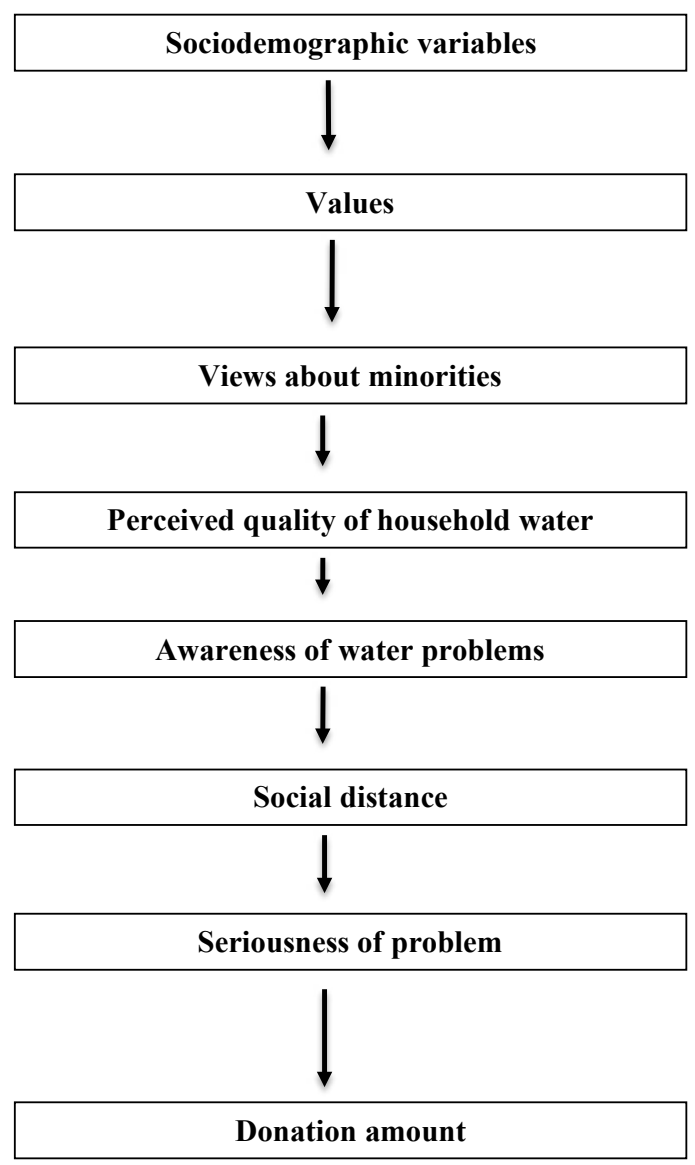

Figure 1. Theoretical model of causal order of factors influencing donation amount

Note. Only proximate causal paths shown. 
Sociodemographic variables. We treat age, gender, education, presence of a child in the household, income, and political ideology as exogenous variables. We include them to guard against potentially spurious conclusions about other variables in the model, in particular, values, symbolic racism, and social distance.

Values. Following the consensus in the literature, values are considered causally subsequent to the demographic variables but causally prior to all other variables in the model (Dietz, 2015).

Symbolic racism. We treat symbolic racism as causally subsequent to values and the sociodemographic variables but causally prior to social distance. Our logic is that these views are a more general concept than social distance from members of the community suffering the water crisis, but less general than values. We acknowledge that this causal ordering, while plausible, could be questioned and that with crosssectional data, we cannot disentangle causal ordering empirically.

Perceived quality of respondents' water. Respondents who believe the quality of their own drinking water is poor might be more sympathetic to a community facing severe contamination. We assessed the perceived quality of the respondents' water, which we consider causally subsequent to the sociodemographic variables, values, and symbolic racism but causally prior to social distance and seriousness of the problem.

General awareness of water problems. We assessed the respondents' awareness of water quality problems in other communities because respondents may be more willing to donate if they perceive the problem to be widespread. We assume general awareness is causally prior to perceived social distance, seriousness of the problem, and donation but causally subsequent to the sociodemographic variables, values, symbolic racism, and perceived water quality.

Social distance. We consider this variable causally subsequent to the sociodemographic variables, values, symbolic racism, and respondents' perception of their water quality, but causally prior to perceived seriousness of the problem and donation amount.

Perceived seriousness of the problem. We presented respondents with a scenario about a water quality problem rather like that in Flint as part of an experimental design that will be described below. We conjecture that the more serious they considered the problem, the more willing they would be to donate. We treat perceived seriousness of the problem as casually subsequent to demographics, values, symbolic racism, and social distance but causally prior to donation.

Donation amount. At the end of the survey, we informed all respondents that we were giving them a $\$ 0.50$ bonus over their basic fee for participating in the survey. We then gave them an opportunity to donate all or part of the bonus to Clean Water 
Action, a non-profit that works to improve water quality in the US using a protocol developed by Clements et al. (2015). We will describe the procedure in greater detail in the Methods section. The donation is an actual donation to a collective good and is considered causally subsequent to all other variables in our model.

\section{Methods}

\section{Data collection and working sample}

We administered our survey using SurveyMonkey to participants we recruited via Amazon Mechanical Turk (AMT), a crowdsourcing website where "requesters" solicit "workers" to perform "human intelligence tasks" (HITs) for pay. AMT is a practical way to recruit participants from a reasonably wide cross-section of the general public, either for conducting online experiments (e.g., Clements et al., 2015) or designing and testing new measurement instruments (e.g., Allen et al., 2015). It has been widely used across the social sciences (Goodman et al., 2013; Levay et al., 2016; Paolacci \& Chandler, 2014; Rouse, 2015; Shank, 2015; Stewart et al., 2015; Weinberg et al., 2014). To solicit a broad cross-section of research participants and minimize self-selection by AMT workers with particularly strong views on water quality issues, we advertised a HIT titled "Your Attitudes about Important Social Issues in the US." We limited participation to adults residing in the US. The first page of the survey provided information to potential respondents about the voluntary nature of the survey and about confidentiality in accordance with the policies of the Institutional Review Board of our university. Our survey was completed by 643 US residents on April 9, 2016. Respondents earned $\$ 1.00$ for completing the survey, which took slightly less than seven minutes on average, for an hourly wage rate of $\$ 8.67$.

Experimental manipulation. Respondents were assigned at random to one of five versions of the survey. The versions were identical except for the description of a community experiencing a drinking water quality problem. The ethnicity of community was varied across the versions of the scenario, which were otherwise identical. The variations are reported in the Annex. ${ }^{2}$ Since the experimental manipulation had no significant effects, we do not discuss it in detail.

Working sample. We have only modest numbers of non-Whites (58 respondents identified as Hispanic, 31 as African-American, and 23 as other racial/ethnic categories). We restrict the sample to Whites, African-Americans and Hispanics,

2 The Annex is available at msu.edu/ -tdietz/Dietz\%20et\%20al\%20Water\%20Quality\%20Supplement.pdf. 
since we do not have enough respondents to examine other groups. We used steps described in the Annex to remove low-quality responses. The result is a working sample of 375 .

\section{Variable measurement}

We have developed scales using the means of all valid responses on items in a scale as the scale score. The reliability of scales was checked with Cronbach's $\alpha$. All scales except "traditionalism" and the scale of awareness of water quality problems in four communities were above the traditional cutpoint for Cronbach's $\alpha$ of 0.70 (Nunally, 1978). Scale items and reliabilities are reported in Annex Table A1. The order in which items within a scale were presented to respondents was randomized across respondents.

Sociodemographic variables. We included several variables to capture position in the social structure. Gender is a binary variable, with women coded 0 and men 1 . Age was measured with eight categories (18-19, 20-29, 30-39, 40-49, 50-59, 50-69, $70-79$, and 80 years and over). An ordinal age variable was created by recoding the categorical responses to the midpoint of their range. Note that in a cross-sectional data set, age is identical with birth cohort. We created a dummy variable if the respondent reported a child under 18 years living in their home. Education is an ordinal variable coded as follows: $1-12$ th grade or less, 2 - high school diploma or General Education Diploma equivalent, 3 - bachelor's degree, 4 - master's degree, 5 - professional degree (e.g., law or medicine), and 6 - doctorate degree. Household income was recorded in five categories: \$0-24,999, \$25,000-49,999, $\$ 50,000-74,999, \$ 75,000-99,999$, and $\$ 100,000$ and up. A continuous income variable was created by assigning the midpoint of the range in thousands, with the highest category assigned 125 . Political ideology was measured with a 1-7 scale, ranging from very liberal to very conservative. Since political ideology and political party identification have a Pearson's correlation of 0.85 , we will only use ideology in our analyses.

In the analyses that follow, we treat age and education as if they were continuous variables. This possibly masks non-linear effects of age or education, but alternative approaches introduce complexities we do not believe are warranted for these control variables. For example, using dummy variables for each ordinal category would increase by about one-third the number of parameters being estimated.

Values. Standard value items were used to assess the six values (Dietz, 2015; Dietz et al., 2017). Respondents were asked to indicate "how important each of the following is as a guiding principle in your life" using a 1-5 scale of "Not at all important," "Minimally important," "Somewhat important," "Moderately important," and 
"Extremely important." For humanistic altruism $\alpha=0.83$; for biospheric altruism $\alpha=0.91$; for self-interest $\alpha=0.75$; for openness to change $\alpha=0.72$; for traditionalism $\alpha=0.58$; and for animal-related values $\alpha=0.87$.

Symbolic racism. We used four items developed by Henry and Sears to tap symbolic racism (2002; Sears \& Henry, 2005). The response choices were "Strongly disagree," "Disagree somewhat," "Neither agree nor disagree," "Agree somewhat," and "Strongly agree," scored 1-5. In our sample, the Cronbach's $\alpha$ for the scale was 0.92 .

Perceived water quality. We used four items to capture the respondents' perceptions of the quality of their own drinking water. Respondents were asked to rate the taste, odor, and visual appearance "of your home water supply (before any in-home filtering)?" Response categories were "Very poor," "Poor," "Adequate," "Good," and "Very good." They were also asked "How safe do you think your drinking water is (before any filtering)? Please answer on a scale of 1-5 where 1 means not at all safe and 5 means perfectly safe." These four items form a scale with Cronbach's $\alpha=0.85$.

General awareness of community water problems. We asked respondents to assess their familiarity with drinking water problems with the following items: "Across the US a number of towns have had drinking water quality problems. How familiar are you with the story of the following water quality problems?" where the specific situations were "Lead contamination in Washington, DC," "Contamination from coal cleaning chemicals in Charleston, West Virginia," "Lead contamination in Jackson, Mississippi," "Contamination from plastics processing chemicals in Hoosick Falls, New York," and "Lead contamination in Flint, Michigan." Response categories were "I have not heard of it," "I have heard of it but am not very familiar with it," "I am somewhat familiar with it," and "I am very familiar with it." We found that familiarity with Flint $(M=3.31)$ was much higher than with the other communities (Ms ranged from 1.30-1.69) and that including Flint in the scale reduced reliability slightly. So, we created the scale with the other four communities and used awareness of Flint as a separate variable, ranging from 1 "I have not heard of it," to 4 - "I am very familiar with it." For the awareness of the four communities, Cronbach's $\alpha=0.73$. The scale and the Flint awareness variable have a Pearson's correlation coefficient of 0.22 .

Social distance. We used three items to capture social distance, one each asking about temporal proximity, spatial proximity, and social proximity to water contamination. Following standard protocols in the social distance literature, each item asserted that water contamination was "close" to the respondent. The response choices were a seven-point scale with 1 anchored at "Not at all accurate" and 7 anchored at "Very accurate." The three-item scale has Cronbach's $\alpha=0.70$. 
Seriousness of the problem. We used seven items to assess perceived seriousness of the problem described in the scenario. Respondents were asked "How serious do you think each aspect of the water quality problem just described is, using a scale that ranges from 1 - Not at all serious to 7 - Extremely serious?" The aspects were: Health risks to children, Health risks to adults, Costs to local government, Harm to the local economy, Harm to property values, Harm to the morale of the residents, and Health risks to pets and companion animals. These items form a scale with Cronbach's $\alpha=0.79$.

Willingness-to-pay measure. As is typical in willingness-to-pay studies, our data has slightly more than half $(52.8 \%)$ our respondents at zero with a median of zero and a mean of 13 . The Annex contains a histogram of the donation amount.

\section{Estimation methods}

As is often the case with willingness-to-pay data, most of the variation in our data set comes from the distinction between not donating and donating some amount. Thus, we analyze our data using two models: a logit model to predict whether someone made any donation and an ordinary least squares (OLS) regression model of the amount donated for those who donated something. We find the same substantive results when we use a hurdle model that estimates whether someone donated and how much they donated simultaneously (Burke, 2009; Cragg, 1971; Smith \& Brame, 2003). Since logit and OLS regression are more familiar than hurdle models to most readers, we report logit and OLS results in our tables. The highest variance inflation factors (VIF) among the independent variables in any model was below 2.7, suggesting no serious collinearity problems.

The first two columns of Table 1 are equivalent to the direct effects for each variable that would be obtained if we used a structural equation model (SEM) estimation procedure rather than logit and OLS regression. The third and fourth columns are equivalent to the total effects of the variables in that column, including both their direct and indirect effects through the variables not included in those two columns. Note that under standard assumptions for inference, logit, OLS regression, hurdle, and typical SEM estimates are all maximum likelihood (Bollen, 1989; Wooldridge, 2002). The advantage of SEM estimation lies in either including an explicit measurement model for latent variables or estimating indirect and mediation effects. Since those are not central concerns to our analysis, we have opted for the simpler approach.

\section{Results of the experiment}

The experiment to determine if varying the racial composition of the community affected by water quality problems influenced donations did not yield significant results. For the five dummy variables capturing the six experimental conditions, 
the effect on whether the respondent donated had $\chi_{4}^{2}=2.04, p=0.728$; the effect on the amount donated has $\mathrm{F}_{4,179}=1.33, p=0.260$. We also found no evidence for experimental effects when the independent variables we included in Table 1 were controlled. Thus, we do not discuss the experiment further.

Table 1. Models of donation and beliefs about minorities

\begin{tabular}{|c|c|c|c|c|}
\hline & $\begin{array}{l}\text { Whether } \\
\text { a donation } \\
\text { was made } \\
\text { (odds ratios) }\end{array}$ & $\begin{array}{c}\begin{array}{c}\text { Amount of } \\
\text { donation } \\
\text { for those }\end{array} \\
\text { donating }>0\end{array}$ & $\begin{array}{l}\text { Whether } \\
\text { a donation } \\
\text { was made } \\
\text { (odds ratios) }\end{array}$ & $\begin{array}{c}\text { Amount of } \\
\text { donation } \\
\text { for those } \\
\text { donating }>0\end{array}$ \\
\hline \multirow[t]{2}{*}{ Seriousness of problem } & 1.21 & 2.03 & - & - \\
\hline & 1.13 & 1.07 & & \\
\hline \multirow{2}{*}{$\begin{array}{l}\text { Awareness of other } \\
\text { communities }\end{array}$} & 1.35 & -2.40 & - & - \\
\hline & 1.44 & -1.08 & & \\
\hline \multirow[t]{2}{*}{ Awareness of Flint } & 1.02 & $3.73^{\star}$ & - & - \\
\hline & 0.11 & 2.33 & & \\
\hline \multirow{2}{*}{$\begin{array}{l}\text { Social distance (high scores } \\
\text { are close) }\end{array}$} & 0.97 & -0.11 & - & - \\
\hline & -0.35 & -0.10 & & \\
\hline \multirow[t]{2}{*}{ Respondent's water quality } & 0.94 & 0.76 & - & - \\
\hline & -0.42 & 0.41 & & - \\
\hline \multirow[t]{2}{*}{ Symbolic racism } & $0.71^{*}$ & -1.97 & - & - \\
\hline & -2.33 & -1.17 & & \\
\hline \multirow[t]{2}{*}{ Biospheric altruism } & 0.94 & 0.10 & 0.96 & 0.84 \\
\hline & -0.33 & 0.05 & -0.25 & 0.41 \\
\hline \multirow[t]{2}{*}{ Humanistic altruism } & 1.23 & -0.31 & $1.57^{\star}$ & 0.87 \\
\hline & 1.03 & -0.12 & 2.54 & 0.36 \\
\hline \multirow[t]{2}{*}{ Self-interest } & 0.87 & -2.54 & 0.85 & $-3.44^{*}$ \\
\hline & -0.89 & -1.44 & -1.11 & -2.02 \\
\hline \multirow[t]{2}{*}{ Traditionalism } & 1.30 & -0.08 & 1.20 & -0.53 \\
\hline & 1.22 & -0.04 & 0.89 & -0.24 \\
\hline \multirow[t]{2}{*}{ Animal concern values } & 1.09 & 1.51 & 1.05 & 1.30 \\
\hline & 0.53 & 0.78 & 0.34 & 0.66 \\
\hline \multirow{2}{*}{$\begin{array}{l}\text { Political ideology (high } \\
\text { scores conservative) }\end{array}$} & 0.94 & 0.81 & 0.86 & 0.44 \\
\hline & -0.65 & 0.73 & -1.72 & 0.44 \\
\hline \multirow[t]{2}{*}{ Female } & 1.37 & 5.51 & 1.50 & $5.74^{\star}$ \\
\hline & 1.27 & 1.96 & 1.70 & 2.08 \\
\hline \multirow[t]{2}{*}{ Age } & 0.99 & -0.02 & 0.99 & 0.03 \\
\hline & -0.98 & -0.17 & -1.02 & 0.26 \\
\hline \multirow[t]{2}{*}{ Child in house } & 1.06 & -4.62 & 0.98 & -5.56 \\
\hline & 0.22 & -1.59 & -0.07 & -1.90 \\
\hline
\end{tabular}




\begin{tabular}{|l|c|c|c|c|}
\hline \multirow{2}{*}{ Education } & $\begin{array}{c}\text { Whether } \\
\text { a donation } \\
\text { was made } \\
\text { (odds ratios) }\end{array}$ & $\begin{array}{c}\text { Amount of } \\
\text { donation } \\
\text { for those } \\
\text { donating }>0\end{array}$ & $\begin{array}{c}\text { Whether } \\
\text { a donation } \\
\text { was made } \\
\text { (odds ratios) }\end{array}$ & $\begin{array}{c}\text { Amount of } \\
\text { donation } \\
\text { for those } \\
\text { donating }>0\end{array}$ \\
\cline { 2 - 5 } Income in thousands & 1.03 & 1.11 & 1.02 & 1.53 \\
\cline { 2 - 5 } & 0.22 & 0.68 & 0.16 & 0.97 \\
\hline African-American & 1.00 & 0.00 & 1.00 & -0.01 \\
\hline \multirow{2}{*}{ Hispanic } & -0.13 & 0.05 & 0.16 & 0.97 \\
\hline Constant & 0.74 & -5.18 & 0.92 & -3.01 \\
\cline { 2 - 5 } & 1.44 & -1.03 & -0.18 & -0.61 \\
\hline $\mathrm{N}$ & 1.17 & 0.02 & 1.48 & 0.96 \\
\hline$R^{2}$ & 0.17 & 0.01 & 1.27 & 0.28 \\
\cline { 2 - 5 } & -1.22 & 0.17 & 0.19 & 17.88 \\
\hline \multirow{2}{*}{$\mathrm{N}$} & 360 & 177 & 361 & 1.50 \\
\hline
\end{tabular}

For logit model of whether a donation was made, coefficients are incidence rate ratios with $\mathrm{z}$ listed below coefficient. For OLS regressions, coefficients are unstandardized, t listed below coefficient ${ }^{*} p<0.05$

\section{Results}

The first and second columns of Table 1 present the results of modeling donation as a function of all independent variables. The only variable influencing whether a respondent was willing to donate is the symbolic racism scale. For each one-point increase on this scale (which ranges from 1-5), willingness to donate is about 70\% less likely. No other variable has effects that approach statistical significance at conventional levels. In the model for the amount donated by those who donated something, only awareness of the problems of Flint has a significant effect at the strict $p=0.05$ level, with each one-point increase on this four-point scale increasing the donation by $\$ 0.037$. The coefficient for gender has $p=0.051$, with women willing to donate $\$ 0.055$ cents more than men, controlling for all other variables in the model.

The third and fourth columns examine the total effects of values and the sociodemographic variables by predicting donations without controls for symbolic racism, perceptions of own water quality, general awareness of the problem, awareness of Flint, perceived social distance, or perceived seriousness of the problem. We include values because they are perhaps the best established social-psychological predictor of pro-environmental behavior. We estimate this model not only because the total effects of these variables are of interest, but also because it allows us to determine if the results are consistent with our theoretical arguments, even if only 
of modest strength. Humanistic altruism has a significant effect on propensity to donate and is the only variable to reach conventional significance levels in that model. Among donators, the amount donated is decreased by self-interest and is higher for women, while the effects of having a child in reducing donations is at the threshold of the conventional 0.05 significance level $(p=0.059)$. These results are consistent with what we might expect from theoretical considerations.

To examine the robustness of our results for symbolic racism, we have used the sensitivity analyses suggested by Frank and colleagues (2013) and implemented in Stata as the "konfound" command (Frank \& Xu, 2017). For the logit model of donation, nearly $18 \%$ of the cases in our data set would have to be replaced with null hypothesis cases before our inference would be invalidated. Put differently, an omitted variable would have to have a partial correlation of about 0.16 with donation and -0.16 with racial beliefs to displace the effects we estimate. Thus, it appears that while our results are by no means unassailable, they are to some degree robust. We also note that symbolic racism demonstrates its effects even with controls for a variety of other variables that often have an influence on pro-environmental behaviors. Conversely, it seems unlikely that symbolic racism is suppressing the effects of other variables via collinearity. The highest VIF in any model is 2.62 for altruism in a model including all the independent variables; in that model, the VIF for symbolic racism is 2.57 and the bivariate correlation between the two is -0.57 . Therefore, it seems plausible that the indirect effects of humanistic altruism come largely through symbolic racism. Finally, our sense that this is a robust finding is bolstered by the consistency of our results with those of Chanin (2018) and Benegal (2018), who used different measures of environmental concern and pro-environmental behavior in nationally representative samples.

\section{Discussion and conclusions}

We have suggested that willingness to support policies to address serious water contamination problems constitutes a collective good problem, and thus might be understood in terms of theories of altruism, including altruistic values, symbolic racism, and social distance. In examining actual donations to a water-focused nongovernmental organization, we found that symbolic racism-views that minorities have received unfair advantage-significantly reduced the chances of a donation being made. This result is consistent with previous examinations of the effect of symbolic racism on policy support. However, to the best of our knowledge, this is the first assessment of the effects of symbolic racism on actual behaviors to support environmental policy and, after Chanin (2018) and Benegal (2018), only the second analysis to consider the effects of racism on environmentalism among the general public. 
Of course, our findings must be viewed as tentative. We have used a convenience sample of moderate size, so we view our results as suggestive, and in need of replication with larger, more representative, and more diverse samples. That said, we do believe our results warrant two tentative conclusions. First, research on the social psychology of environmental concern and environmental racism and justice have been rather distinct traditions with essentially no overlap. Here, we show that environmental justice and the key theoretical issue in the environmental decisionmaking literature, altruism, can be fruitfully incorporated into the same theoretical frame. Second, we offer evidence that environmental racism may influence not only specific cases of inequity well documented in the literature, but broad policy support as well. If our results generalize, they suggest that one reason it continues to be hard to redress key environmental problems in general and environmental justice issues in particular is that support for such redress is influenced by negative attitudes toward minorities. In at least some members of the public, there seems to be a presumed association between environmental problems and minority status.

The theoretical literature on altruism has emphasized the importance of defining the group toward which one behaves altruistically. However, in the extensive literature on altruistic values, altruism has been conceptualized as extending to all humans; indeed, it is sometimes labeled "universalism" (Schwartz 2015). Our results are consistent with the larger literature in that broad altruism is a strong influence on donations. They also demonstrate that the effect of broad altruism can be countered by negative views toward specific groups, in this case minorities. Clearly, further empirical and theoretical work needs to better integrate our understanding of altruism with research on environmental racism and other forms of bias. Environmental justice literature has documented the influence of bias on policies as they are developed and implemented. Our results suggest they may also influence policy support. Given that we only examined one environmental problem—contaminated water-it will be useful to see how broadly these results generalize across other problems that may be less associated with minority communities. It would also be useful to investigate in more detail who members of the public believe will benefit from or bear the costs of environmental policies.

\section{Acknowledgments}

This research was supported in part by Michigan AgBio Research and the Environmental Science and Policy Program, both of Michigan State University. The authors declare they have no actual or potential competing financial interests. 


\section{References}

Allen, S., Dietz, T., \& McCright, A. M. (2015). Measuring household energy efficiency behaviors with attention to behavioral plasticity in the United States. Energy Research and Social Science, 10, 133-140. doi.org/10.1016/j.erss.2015.07.014

Andrews, R. N. L. (1999). Managing the environment, managing ourselves: A history of American environmental policy. New Haven, CT: Yale University Press. doi.org/10.2307/ j.ctt2250wm9

Balazs, C. L., \& Ray, I. (2014). The drinking water disparities framework: On the origins and persistence of inequities in exposure. American Journal of Public Health, 104(4), 603-611. doi.org/10.2105/AJPH.2013.301664

Benegal, S. D. (2018). The spillover of race and racial attitudes into public opinion about climate change. Environmental Politics 27(4), 733-756. doi.org/10.1080/09644016.20 18.1457287

Berg, J. A. (2013). Opposition to pro-immigrant public policy: Symbolic racism and group threat. Sociological Inquiry, 83(1), 1-31. doi.org/10.1111/j.1475-682x.2012.00437.x

Bollen, K. A. (1989). Structural equation models with latent variables. New York, NY: John Wiley and Sons.

Bouffard, K. (2016). Mona Hanna-Attisha: Resolve exposed Flint water crisis. The Detroit News. Detroit, MI.

Buckler, K., Wilson, S., \& Ross Salinas, P. (2009). Public support for punishment and progressive criminal justice policy preferences: The role of symbolic racism and negative racial stereotype. American Journal of Criminal Justice, 34(3-4), 238-252. doi.org/ $10.1007 / \mathrm{s} 12103-008-9056-9$

Burke, W. J. (2009). Fitting and interpreting Cragg's tobit alternative using Stata. Stata Journal, 9(4), 584.

Busse, M., \& Menzel, S. (2014). The role of perceived socio-spatial distance in adolescents' willingness to engage in pro-environmental behavior. Journal of Environmental Psychology, 40, 412-420. doi.org/10.1016/j.jenvp.2014.10.002

Chanin, J. (2018). The effect of symbolic racism on environmental concern and environmental action. Environmental Sociology, 1-13. doi.org/10.1080/23251042.2018.1449340

City of Flint. (2015). State of emergency declared in the City of Flint. Michigan. Retrieved from: www.cityofflint.com/state-of-emergency/

Clements, J. M., McCright, A. M., Dietz, T., \& Marquart-Pyatt, S. (2015). A behavioural measure of environmental decision-making for social surveys. Environmental Sociology, 1(1), 27-37. doi.org/10.1080/23251042.2015.1020466 
Cragg, J. G. (1971). Some statistical models for limited dependent variables with application to the demand for durable goods. Econometrica: Journal of the Econometric Society, 39(5), 829-844. doi.org/10.2307/1909582

Dietz, T. (2015). Environmental values. In T. Brosch and D. Sander (Eds.), Oxford handbook of values (pp. 329-349). Oxford: Oxford University Press. doi.org/10.1093/ acprof:oso/9780198716600.003.0016

Dietz, T., Allen, S., \& McCright, A. M. (2017). Integrating concern for animals into personal values. Anthrozoös, 30(1), 109-122. doi.org/10.1080/08927936.2017.1270597

Dietz, T., Fitzgerald, A., \& Shwom, R. (2005). Environmental values. Annual Review of Environment and Resources, 30, 335-372. doi.org/10.1146/annurev.energy.30.050504. 144444

Downey, L. (2015). Inequality, democracy, and the environment. New York, NY: NYU Press. doi.org/10.18574/nyu/9781479850723.001.0001

Frank, K. A., Maroulis, S., Duong, M. Q., \& Kelcey, B. (2013). What would it take to change an inference? Using Rubin's causal model to interpret the robustness of causal inferences. Educational Evaluation and Policy Analysis, 35, 437-460.

Frank, K. A., \& Xu, R. (2017). Konfound: Stata module to quantify robustness of causal inferences. Statistical Software Components S458298. Boston: Boston College Department of Economics.

Goodman, J. K., Cryder, C. E., \& Cheema, A. (2013). Data collection in a flat world: The strengths and weaknesses of Mechanical Turk samples. Journal of Behavioral Decision Making, 26(3), 213-224. doi.org/10.1002/bdm.1753

Hanna-Attisha, M. (2018). What the eyes don't see: A story of crisis, resistance, and hope in an American city. New York, NY: Random House.

Hart, P. S., \& Nisbet, E. C. (2012). Boomerang effects in science communication: How motivated reasoning and identity cues amplify opinion polarization about climate mitigation policies. Communication Research, 39(6), 701-723. doi.org/10.1177/ 0093650211416646

Henry, P. J., \& Sears, D. O. (2002). The symbolic racism 2000 scale. Political Psychology, 23(2), 253-283. doi.org/10.1111/0162-895X.00281

Holifield, R., Chakraborty, J., \& Walker, G. (2017). The Routledge handbook of environmental justice. New York, NY: Routledge.

Levay, K. E., Freese, J., \& Druckman, J. N. (2016). The demographic and political composition of Mechanical Turk samples. SAGE Open, 6(1): 2158244016636433. doi.org/10.1177/2158244016636433

Livengood, C. (2016). Flint Mayor: Water fix could cost as much as $\$ 1.5 \mathrm{~b}$. The Detroit News, 8 January. Retrieved from: www.detroitnews.com/story/news/politics/2016/01/07/flintwater/78404218/ 
Logan, C., \& Walker, C. (2016). Africa Is failing people on this important development goal. World Economic Forum, Vol. 2016. Geneva: World Economic Forum.

Mascarenhas, M. J. (2016). Where the waters divide: Neoliberal racism, white privilege and environmental injustice. Race, Gender \& Class, 23(3/4), 6-25.

McDonald, R. I., Chai, H. Y., \& Newell, B. R. (2015). Personal experience and the "psychological distance" of climate change: An integrative review. Journal of Environmental Psychology, 44, 109-118. doi.org/10.1016/j.jenvp.2015.10.003

Michigan Legislature Joint Select Committee on the Flint Water Public Health Emergency. (2016). Flint water crisis: Report of the Joint Select Committee on the Flint Water Emergency. Lansing, MI: Michigan Legislature Joint Select Committee on the Flint Water Public Health Emergency.

Nunally, J. C. (1978). Psychometric theory. Englewood Cliffs, NJ: McGraw Hill Book Company.

O’Brien, K., Forrest, W., Lynott, D., \& Daly, M. (2013). Racism, gun ownership and gun control: Biased attitudes in US Whites may influence policy decisions. PLoS One, 8(10), e77552. doi.org/10.1371/journal.pone.0077552

Pahl, S., \& Bauer, J. (2013). Overcoming the distance: Perspective taking with future humans improves environmental engagement. Environment and Behavior, 45(2), 155-169. doi.org/10.1177/0013916511417618

Paolacci, G., \& Chandler, J. (2014). Inside the Turk: Understanding Mechanical Turk as a participant pool. Current Directions in Psychological Science, 23(3), 184-188. doi.org/ $10.1177 / 0963721414531598$

Richerson, P. J., Baldini, R., Bell, A. V., Demps, K., Frost, K., Hillis, V., Mathew, S., Newton, E. K., Naar, N., \& Newson, L. (2016). Cultural group selection plays an essential role in explaining human cooperation: A sketch of the evidence. Behavioral and Brain Sciences, 39. doi.org/10.1017/S0140525X1400106X

Richerson, P. J., \& Boyd, R. (2001). The biology of subjective commitment to groups: A tribal social instincts hypothesis. In R. M Neese (Ed.), Evolution and the capacity for commitment (pp. 186-220). New York, NY: Russell Sage Foundation.

Richerson, P. J., Boyd, R., \& Paciotti, B. (2002). An evolutionary theory of commons management. In E. Ostrom, T. Dietz, N. Dolsak, P. C. Stern, S. Stonich, \& E. Weber (Eds.), The drama of the commons (pp. 403-442). Washington, DC: National Academy Press.

Rouse, S. V. (2015). A reliability analysis of Mechanical Turk data. Computers in Human Behavior, 43, 304-307. doi.org/10.1016/j.chb.2014.11.004

Schwartz, S. H. (2015). Basic individual values: Sources and consequences. In T. Brosch, \& D. Sander (Eds.), Oxford handbook of values (pp. 63-84). Oxford: Oxford University Press. doi.org/10.1093/acprof:oso/9780198716600.003.0004 
Sears, D. O., \& Henry, P. J. (2005). Over thirty years later: A contemporary look at symbolic racism and its critics. Advances in Experimental Social Psychology, 37, 95-150. doi.org/ $10.1016 /$ S0065-2601(05)37002-X

Shank, D. B. (2015). Using crowdsourcing websites for sociological research: The case of Amazon Mechanical Turk. The American Sociologist,1-9.

Smith, D. A., \& Brame, R. (2003). Tobit models in social science research: Some limitations and a more general alternative. Sociological Methods \& Research, 31(3), 364-388. doi.org/ $10.1177 / 0049124102239080$

So, J., \& Nabi, R. (2013). Reduction of perceived social distance as an explanation for media's influence on personal risk perceptions: A test of the risk convergence model. Human Communication Research, 39(3), 317-338. doi.org/10.1111/hcre.12005

Steg, L. (2016). Values, norms, and instrinsic motivation to act pro-environmentally. Annual Review of Environment and Resources, 41, 277-292. doi.org/10.1146/annurevenviron-110615-085947

Steg, L., \& de Groot, J. I. M. (2012). Environmental values. In S. Clayton (Ed.), The Oxford handbook of environmental and conservation psychology (pp. 81-92). New York, NY: Oxford University Press. doi.org/10.1093/oxfordhb/9780199733026.013.0005

Stephan, E., Liberman, N., \& Trope, Y. (2011). The effects of time perspective and level of construal on social distance. Journal of Experimental Social Psychology, 47(2), 397-402. doi.org/10.1016/j.jesp.2010.11.001

Stewart, N., Ungemach, C., Harris, A. J. L., Bartels, D. M., Newell, B. R., Paolacci G., \& Chandler, J. (2015). The average laboratory samples a population of 7,300 Amazon Mechanical Turk workers. Judgment and Decision Making, 10(5), 479-491.

Tarman, C., \& Sears, D. O. (2005). The conceptualization and measurement of symbolic racism. The Journal of Politics, 67(03), pp. 731-761. doi.org/10.1111/j.1468-2508. 2005.00337.x

Trope, Y., \& Liberman, N. (2010). Construal-level theory of psychological distance. Psychological Review, 117(2), 440. doi.org/10.1037/a0018963

United Nations. (2010). The human right to water and sanitation. New York, NY: United Nations General Assembly. Retrieved from: www.un.org/en/ga/search/view_doc.asp? symbol=A/RES/64/292

US Environmental Protection Agency. (2016). Drinking Water State Revolving Fund National Information Management System Reports. Washington, DC: US Enviromental Protection Agency.

US Environmental Protection Agency Office of the Inspector General. (2016). Management alert: Drinking water contamination in Flint, Michigan, demonstrates a need to clarify EPA authority to issue emergency orders to protect the public. Washington, DC: US Environmental Protection Agency, Office of the Inspector General. 
Vorosmarty, C. J., Hoekstra, A. Y., Bunn, S. E., Conway, D., \& Gupta, J. (2015). Fresh water goes global. Science, 349(6247), 478-479. doi.org/10.1126/science.aac6009

Weinberg, J. D., Freese, J., \& McElhattan, D. (2014). Comparing data characteristics and results of an online factorial survey between a population-based and a crowdsourcerecruited sample. Sociological Science, 1, 292-310. doi.org/10.15195/v1.a19

Wooldridge, J. M. (2002). Econometric analysis of cross section and panel data. Cambridge, MA: The MIT Press.

Zigerell, L. J. (2015). Distinguishing racism from ideology: A methodological inquiry. Political Research Quarterly, 68(3), 521-536. doi.org/10.1177/1065912915586631

Zwickle, A., \& Wilson, R. S. (2013). Construing risk. Effective Risk Communication, 190-203. 
This text is taken from Human Ecology Review, Volume 24, Number 1, 2018, published 2018 by ANU Press, The Australian National University, Canberra, Australia.

doi.org/10.22459/HER.24.01.2018.03 